\title{
PRINCIPAIS GESTOS ESPORTIVOS EXECUTADOS POR JOGADORES DE HANDEBOL
}

\author{
MS. LUIZ CARLOS HESPANHOL JUNIOR \\ Mestre em Fisioterapia pelo Programa de Mestrado em Fisioterapia da Universidade \\ Cidade de São Paulo (UNICID) (São Paulo - São Paulo - Brasil) \\ E-mail: luca_hespanhol@hotmail.com
}

\author{
FT. NATALIA GIROTTO \\ Aluna do Programa de Mestrado em Fisioterapia da Universidade Cidade de São Paulo (UNICID) \\ (São Paulo - São Paulo - Brasil) \\ E-mail: girotto.natalia@gmail.com
}

FT. TIAGO NOVATO DE ALENCAR

Fisioterapeuta formado pela Universidade Metodista de São Paulo (UMESP)

(São Paulo - São Paulo - Brasil)

E-mail: tiago.novato.alencar@hotmail.com

\section{DR. ALEXANDRE DIAS LOPES}

Professor do Programa de Mestrado em Fisioterapia da Universidade Cidade de São Paulo (UNICID), Doutor em Biodinâmica do Movimento Humano pela Universidade de São Paulo (USP) (São Paulo - São Paulo - Brasil)

E-mail: aledlopes@yahoo.com.br

\section{RESUMO}

Este estudo teve como objetivo quantificar os principais gestos esportivos executados por jogadores profissionais de handebol. Para a mensuração quantitativa dos principais movimentos executados por cada jogador de handebol avaliado foram realizadas gravações de vídeo em todos os jogos. Foram realizados em média 1288,0 (DP $=190,7)$ gestos esportivos por jogo. Os armadores centrais realizaram em média 375,0 (DP $=83,7)$ gestos esportivos, e a posição de pivô 63,3 (DP = 21,2) gestos por jogo. As recepções e os passes foram os gestos mais executados, e a posição que mais realizou gestos esportivos na equipe de handebol avaliada foi o armador central, seguido do armador esquerdo e direito. O pivô foi a posição que menos realizou gestos esportivos.

PALAVRAS-CHAVE: Atletas; desempenho atlético; movimento; gravação em vídeo. 
O handebol é um esporte de quadra que envolve duas equipes de sete jogadores. Este esporte propicia movimentos de corrida, saltos e arremessos. A corrida em geral é o fundamento mais utilizado no handebol, sendo permitido progredir driblando com batidas de bola sucessivas. Os jogadores não devem reter a bola por mais que três segundos sem realizar as batidas, sendo permitido até três passos com a bola na mão, para então soltá-la ou arremessá-la (FACCA; BORSARI; NEVES FILHO, 1977). No entanto, para cumprir o objetivo do jogo, que é a marcação de gols, os jogadores da equipe devem combinar técnicas de ataque iniciando pelo domínio do passe, recepção, finta e arremesso (REIS, 2006). Em oposição, na situação de defesa (p. ex., equipe sem posse de bola) os jogadores procuram evitar que um atacante da equipe adversária se posicione ou consiga uma situação favorável para finalização, utilizando técnicas defensivas, tais como, deslocamentos, bloqueios e marcações (ZAMBERLAN, 1999).

A velocidade de realização dos gestos esportivos que caracteriza o handebol é elevada em níveis competitivos e de elite (FERREIRA FILHO; SOUSA; GRECO, 200 I). Contudo, a questão que se coloca é se a quantidade de movimentos (gestos esportivos) que os jogadores executam durante os jogos de handebol têm alguma relação com o surgimento de lesões. A literatura aponta que, em jogadores de handebol, a prevalência de lesões em membros inferiores varia entre 11,9\% a 67\%, e em membros superiores varia entre 7,5\% e 40\% (WEDDERKOPP et al., 1997; ASEMBO; WEKESA, 1998).

$\bigcirc$ estudo da quantidade de movimentos realizados pelos praticantes de handebol é necessário para auxiliar na adoção de estratégias mais eficazes de treinamento e/ou de prevenção de lesões durante a prática do handebol, pois o conhecimento da demanda imposta ao sistema musculoesquelético dos jogadores de handebol durante o jogo pode auxiliar na elaboração de estratégias preventivas mais eficazes. Os movimentos dos jogadores de handebol podem ser avaliados de forma quantitativa ou qualitativa, através da observação dos jogos (GRECO, 1990). Assim, este estudo tem como objetivo quantificar os principais gestos esportivos executados por jogadores profissionais de handebol durante jogos oficiais.

\section{MATERIAL E MÉTODOS}

\section{AMOSTRA}

Essa pesquisa é um estudo transversal descritivo, realizado durante as finais do Campeonato Paulista promovido pela Federação Paulista de Handebol - FPH no 
ano de 2002. O trabalho foi realizado com os doze atletas de handebol masculino com idade adulta, e pertencentes à equipe da Universidade Metodista de São Paulo que estavam inscritos para as partidas finais do campeonato. Este estudo obteve aprovação do Comitê de Ética da Universidade Metodista de São Paulo (UMESP), dentro dos termos da Resolução 196/96 e 25 I/97 do Conselho Nacional de Saúde. Para cada uma das seis posições avaliadas foram analisados dois atletas (um titular e um reserva), sendo que a posição do goleiro não foi avaliada neste estudo.

\section{INSTRUMENTAÇÃO E PROCEDIMENTO}

Os dados desse estudo são referentes aos movimentos dos jogadores da equipe de handebol da Universidade Metodista de São Paulo (UMESP), realizados durante os quatro jogos finais do Campeonato Paulista de Handebol. Para a mensuração quantitativa dos principais movimentos executados, assim como para o controle do tempo de permanência em quadra de cada jogador, foram feitas gravações de vídeo em todos os quatro jogos avaliados. Posteriormente, as imagens foram analisadas com uma ficha individual (ver ANEXO A), que foi preenchida sempre pelo mesmo avaliador.

Os gestos esportivos (variáveis) consideradas no estudo foram: (I) saltos (ação de deslocar o corpo no ar utilizando a impulsão de uma ou duas pernas em várias direções); (2) arremesso por cima (ação realizada com intenção da marcação de gol, e apenas com uma mão que se posiciona acima da cabeça); (3) arremesso por baixo (ação realizada com intenção da marcação de gol, e apenas com uma mão que se posiciona na linha da cintura); (4) passe (ação de arremesso sem intenção de gol com o objetivo de entregar a bola a um companheiro de equipe); (5) recepção (ação realizada com as mãos ligeiramente paralelas e em formato côncavo, mas também pode ser realizada com apenas uma mão); e (6) fintas (ação realizada com a posse da bola, que é o movimento do jogador realizado em no máximo três passos na tentativa de fintar seu adversário) (TENROLER, 2004; REIS, 2006). Para cada jogador também foi realizado o controle do tempo de permanência em quadra.

\section{ANÁLISE ESTATÍSTICA}

A análise dos dados foi realizada pela estatística descritiva, com uma medida de tendência central (média) e uma medida de dispersão (desvio-padrão) para os dados dos gestos esportivos, tempo de execução do gesto esportivo e tempo de 
permanência em quadra de cada jogador. A distribuição de frequências (porcentagem) de cada gesto esportivo também foi realizada. Os dados estão apresentados por posição de cada atleta, diferenciando os movimentos entre os jogadores titulares e reservas.

\section{RESULTADOS}

No total foram realizados 5.152 gestos esportivos durante os quatro jogos, sendo que 309 foram saltos (232 dos jogadores titulares e 77 dos reservas), 197 arremessos por cima ( 152 dos titulares e 45 dos reservas), 27 arremessos por baixo (todos dos jogadores titulares), 2.064 passes ( 1.736 dos titulares e 328 dos reservas), 2. 1 I 9 recepções ( 1.775 dos titulares e 344 dos reservas) e 436 fintas com posse de bola (367 dos titulares e 69 dos jogadores reservas). A Tabela I apresenta a média e o desvio-padrão de cada gesto esportivo (sendo que na maioria das vezes foram realizados movimentos simultâneos) e o tempo médio de execução de cada gesto para cada jogador.

Em média foram realizados 1.288,0 (DP $=190,7$ ) gestos esportivos por jogo ou 2 | 4,7 (DP = |40, I) gestos esportivos por jogador em cada jogo. Foi possível observar que os armadores, principalmente o armador central, realizaram a maior quantidade de gestos esportivos. $\bigcirc$ pivô titular e reserva foram os que menos realizaram gestos na média total, apresentando um maior tempo médio para realização de um gesto. O maior tempo de permanência em quadra foi do armador esquerdo titular e o menor foi do ponta esquerda reserva (TABELA 2). A Figura I apresenta a porcentagem de cada gesto esportivo avaliado, demonstrando a proporção de execução de cada gesto esportivo por jogo. 


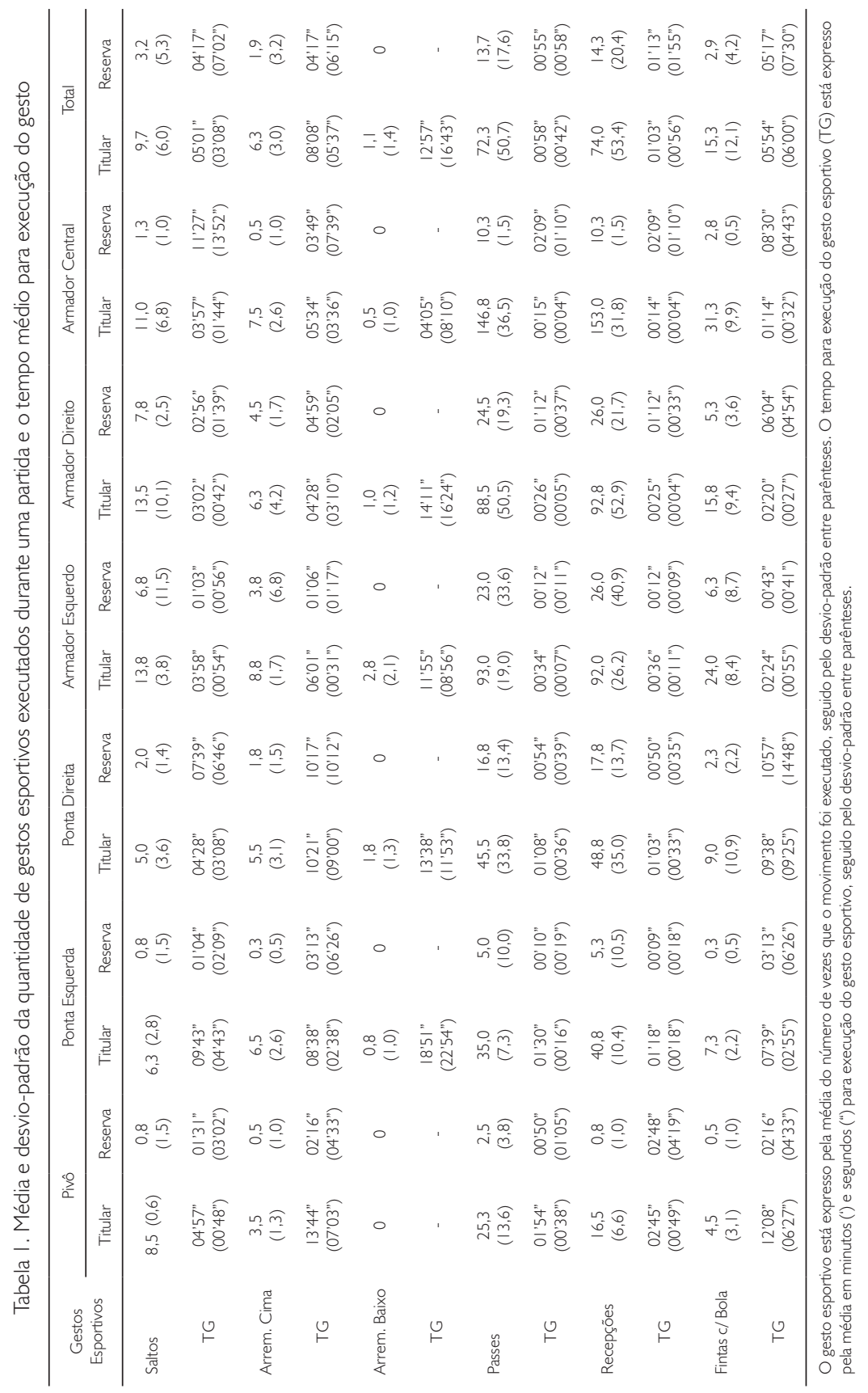


Tabela 2. Média e desvio-padrão de gestos esportivos, tempo de cada gesto e tempo de permanência em quadra

\begin{tabular}{|c|c|c|c|c|c|c|c|c|c|}
\hline \multirow{2}{*}{ Posição } & \multicolumn{3}{|c|}{ Todos } & \multicolumn{3}{|c|}{ Titular } & \multicolumn{3}{|c|}{ Reserva } \\
\hline & Gestos & TG & TPQ & Gestos & TG & TPQ & Gestos & TG & TPQ \\
\hline Pivô & $\begin{array}{c}63,3 \\
(21,2)\end{array}$ & $\begin{array}{c}47 " \\
(|| ")\end{array}$ & $\begin{array}{c}46^{\prime} 46^{\prime \prime} \\
\left(06^{\prime} 20 "\right)\end{array}$ & $\begin{array}{c}58,3 \\
(21,6)\end{array}$ & $\begin{array}{c}46 " \\
(1 \mid ")\end{array}$ & $\begin{array}{c}4 \text { l'42" } \\
\text { (04'29") }\end{array}$ & $\begin{array}{c}5,0 \\
(8,1)\end{array}$ & $\begin{array}{c}53 " \\
(32 ")\end{array}$ & $\begin{array}{c}05^{\prime} 04^{\prime \prime} \\
\left(08^{\prime} 48^{\prime \prime}\right)\end{array}$ \\
\hline $\begin{array}{l}\text { Ponta } \\
\text { Esquerda }\end{array}$ & $\begin{array}{l}108,0 \\
(32,7)\end{array}$ & $\begin{array}{c}32 " \\
(08 ")\end{array}$ & $\begin{array}{c}54^{\prime} \mid 3^{\prime \prime} \\
\left(066^{\prime} 0 I^{\prime \prime}\right)\end{array}$ & $\begin{array}{c}96,5 \\
(22,2)\end{array}$ & $\begin{array}{c}33 " \\
(07 ")\end{array}$ & $\begin{array}{c}5 \text { I'00" } \\
(05 \text { '27") }\end{array}$ & $\begin{array}{c}11,5 \\
(23,0)\end{array}$ & $\begin{array}{l}17 " \\
(08 ")\end{array}$ & $\begin{array}{c}03^{\prime} \mid 3^{\prime \prime} \\
\left(06^{\prime} 26^{\prime \prime}\right)\end{array}$ \\
\hline $\begin{array}{l}\text { Ponta } \\
\text { Direita }\end{array}$ & $\begin{array}{l}156,0 \\
(79,1)\end{array}$ & $\begin{array}{c}25 " \\
(10 ")\end{array}$ & $\begin{array}{c}\text { 55'।7" } \\
\text { (04'30") }\end{array}$ & $\begin{array}{l}115,5 \\
(75,2)\end{array}$ & $\begin{array}{c}26 " \\
(16 ")\end{array}$ & $\begin{array}{c}36^{\prime} 26^{\prime \prime} \\
\left(16^{\prime} \mid 0^{\prime \prime}\right)\end{array}$ & $\begin{array}{c}40,5 \\
(30,2)\end{array}$ & $\begin{array}{c}28 " \\
\left(15^{\prime \prime}\right)\end{array}$ & $\begin{array}{c}\text { | 8'5 |" } \\
(\mid 3 \text { '52") }\end{array}$ \\
\hline $\begin{array}{l}\text { Armador } \\
\text { Esquerdo }\end{array}$ & $\begin{array}{c}300,0 \\
(1 \mid 1,4)\end{array}$ & $\begin{array}{c}\text { 13" } \\
(02 ")\end{array}$ & $\begin{array}{c}60^{\prime} 45^{\prime \prime} \\
(10 ' 54 ")\end{array}$ & $\begin{array}{l}234,3 \\
(38,7)\end{array}$ & $\begin{array}{c}14 " \\
(02 ")\end{array}$ & $\begin{array}{c}52^{\prime} 00 " \\
\left(05^{\prime} 4 I^{\prime \prime}\right)\end{array}$ & $\begin{array}{c}65,6 \\
(101,4)\end{array}$ & $\begin{array}{c}06 " \\
(04 ")\end{array}$ & $\begin{array}{c}08^{\prime} 45^{\prime \prime} \\
\left(15^{\prime} 08^{\prime \prime}\right)\end{array}$ \\
\hline $\begin{array}{l}\text { Armador } \\
\text { Direito }\end{array}$ & $\begin{array}{c}285,8 \\
(|| \mid, 3)\end{array}$ & $\begin{array}{c}\text { | 8" } \\
(|| ")\end{array}$ & $\begin{array}{c}\text { 60'26" } \\
\text { ( | |'56") }\end{array}$ & $\begin{array}{c}217,8 \\
(125,4)\end{array}$ & $\begin{array}{c}\text { l0" } \\
(0 \mid ")\end{array}$ & $\begin{array}{c}38^{\prime} 43^{\prime \prime} \\
\left(24^{\prime} \mid 6^{\prime \prime}\right)\end{array}$ & $\begin{array}{c}68,0 \\
(25,6)\end{array}$ & $\begin{array}{c}22 " \\
(06 ")\end{array}$ & $\begin{array}{l}22^{\prime} 43^{\prime \prime} \\
\left(12^{\prime} 57^{\prime \prime}\right)\end{array}$ \\
\hline $\begin{array}{l}\text { Armador } \\
\text { Central }\end{array}$ & $\begin{array}{l}375,0 \\
(83,7)\end{array}$ & $\begin{array}{c}\text { 09" } \\
(02 ")\end{array}$ & $\begin{array}{c}57^{\prime} \mid 9^{\prime \prime} \\
\left(05^{\prime} 58^{\prime \prime}\right)\end{array}$ & $\begin{array}{l}350,0 \\
(84,5)\end{array}$ & $\begin{array}{c}06 " \\
(02 ")\end{array}$ & $\begin{array}{c}34^{\prime} 59^{\prime \prime} \\
\left(05^{\prime} 44^{\prime \prime}\right)\end{array}$ & $\begin{array}{l}25,0 \\
(1,8)\end{array}$ & $\begin{array}{c}53 " \\
(27 ")\end{array}$ & $\begin{array}{l}\text { 22'20" } \\
\text { ( I |'38") }\end{array}$ \\
\hline Total & $\begin{array}{c}1288 \\
(190,7)\end{array}$ & $\begin{array}{c}24 " \\
(04 ")\end{array}$ & $\begin{array}{c}53 \text { '23" } \\
\text { (05'0I") }\end{array}$ & $\begin{array}{l}1072,3 \\
(70,3)\end{array}$ & $\begin{array}{c}23 " \\
(15 ")\end{array}$ & $\begin{array}{c}\text { 42'28" } \\
\text { (13'09") }\end{array}$ & $\begin{array}{c}215,8 \\
(134,9)\end{array}$ & $\begin{array}{c}30 " \\
(19 ")\end{array}$ & $\begin{array}{c}13^{\prime} 29^{\prime \prime} \\
\left(13^{\prime} 20^{\prime \prime}\right)\end{array}$ \\
\hline
\end{tabular}

As colunas "gestos" apresentam as médias (desvio-padrão) do número total de execução dos gestos esportivos por jogo. As colunas "TG" (tempo para execução do gesto esportivo) apresentam as médias (desvio-padrão) do tempo necessário para se realizar um gesto esportivo por jogo. As colunas TPQ (tempo de permanência em quadra) apresentam as médias (desvio-padrão) do tempo de permanência em quadra por jogo. O símbolo (") representa os minutos. O símbolo (") representa os segundos.

Pivô

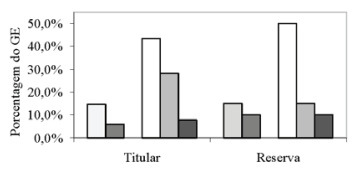

Armador Esquerdo

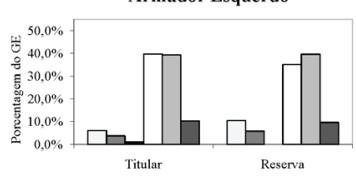

$\square$ Saltos $\quad \square$ Arremessos por cima

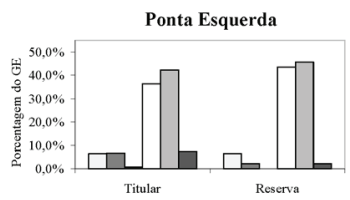

Armador Direito

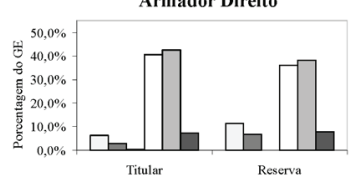

Arremessos por baixo $\square$ Passes

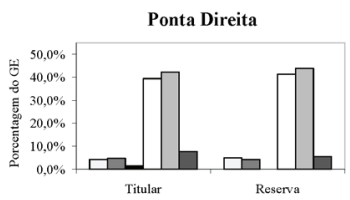

Armador Central

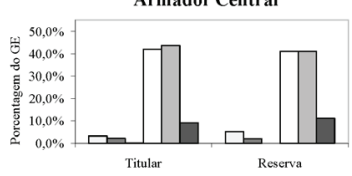

$\square$ Recepções

Figura I. Porcentagem de cada gesto esportivo (GE) realizado por jogo pelos jogadores de handebol. 


\section{DISCUSSÃO}

A mensuração dos gestos esportivos no handebol foi realizada durante os quatro jogos finais do Campeonato Paulista que contaram com a participação da equipe da UMESP. Foram quantificados os números de saltos, arremessos por cima da cabeça, arremessos por baixo da cabeça, passes, recepções, fintas com a posse de bola, o tempo por gesto esportivo de cada jogador e o tempo de permanência em quadra. Foram realizados em média I.288,0 (DP = 190,7) gestos esportivos por jogo, sendo que os armadores foram os jogadores que mais realizaram esses gestos. Os armadores centrais foram os jogadores com menor tempo para execução de um gesto esportivo, e o maior tempo de permanência em quadra foi do armador esquerdo titular.

A posição de pivô foi a que menos realizou gestos esportivos, como pode ser visto na quantidade média de gestos esportivos totais e no tempo para realizar um gesto esportivo. Esses jogadores também foram os que menos atacaram na equipe, pois apresentaram um número baixo de arremessos por cima e por baixo, além dos passes e recepções terem sido os gestos mais executados por estes jogadores. Os poucos gestos executados por estes jogadores podem estar relacionados à pouca participação nas armações das jogadas, e talvez por ser uma posição que tem uma maior importância tática de marcação e de distração do adversário.

Depois do pivô, os pontas foram os que menos realizaram gestos esportivos e arremessos e, assim como o pivô, os pontas não participaram com muita frequência da armação das jogadas. Os pontas direita e esquerda geralmente são responsáveis pelas finalizações nas pontas da quadra, mas foi observado que os jogadores dessas posições não foram os principais finalizadores da equipe. Porém, o ponta esquerda titular realizou um número de arremessos por cima semelhante ao armador direito titular. Como o armador esquerdo titular foi o que mais realizou arremessos por cima e por baixo, de toda a equipe, isso pode indicar que a maioria das jogadas de finalização foram realizadas pelos jogadores do setor esquerdo dessa equipe de handebol.

Os armadores foram os que mais realizaram gestos esportivos no geral, e foram os principais finalizadores da equipe junto com o ponta esquerda, como pode ser visto pela média de arremessos por cima realizados por esses jogadores. Porém, os arremessos não foram os principais gestos desses jogadores, sendo as recepções e os passes os principais gestos esportivos executados por eles e por todos os outros jogadores da equipe de handebol avaliada. Geralmente os armadores realizavam um grande número de passes e recepções durante um curto espaço de tempo. Isso indica que os armadores foram os principais responsáveis pela armação das 
jogadas, visto que dificilmente uma jogada era construída sem que a bola passasse pelas suas mãos.

Ormador esquerdo titular foi o finalizador da equipe com a maior média em arremessos por cima da cabeça, por baixo e de saltos, além de ser o segundo em fintas com posse de bola, demonstrando sua função ofensiva na equipe. Os armadores esquerdo titular e reserva apresentaram poucas diferenças, porém o armador reserva estava voltando de uma lesão em seu ombro, fato esse que pode ter contribuído para uma subestimação dos resultados, quando analisada essa posição. $\bigcirc$ armador direito foi o segundo principal saltador da equipe. $\bigcirc$ armador central titular foi o jogador que mais realizou gestos esportivos em geral e o que mais passava e recepcionava, confirmando sua principal função, a armação da jogada.

Os jogadores de handebol deste estudo tiveram um predomínio de movimentação baseada nos membros superiores, apesar da literatura demonstrar que as maiores taxas de lesões ocorrem em membros inferiores, sendo elas as entorses de tornozelo e as lesões ligamentares do joelho principalmente (HOEBERIGS; VAN GALEN; PHILIPSEN, 1986; WEDDERKOPP et al., 1997; SEIL et al., I998; TEGNANDER et al., 2008). Acreditamos que o fato da maioria das lesões do handebol ocorrer devido a um macrotrauma no membro inferior (JUNGE et al., 2009) possa justificar esse aparente paradoxo, sendo que essas lesões traumáticas em membros inferiores superam em gravidade e em quantidade qualquer afecção musculoesquelética que eventualmente poderia estar relacionada com esse grande número de gestos esportivos realizados com o membro superior.

Infelizmente, a literatura sobre estudos com objetivos semelhantes ao que se propõe este estudo é escassa, o que prejudicou a discussão dos resultados encontrados nesse estudo, não permitindo que pudéssemos confrontar nossos achados com a literatura. Sugerimos que outros estudos sejam conduzidos com objetivos semelhantes, envolvendo um número maior de equipes e jogos avaliados, além da inclusão de outras variáveis, como a distância percorrida na quadra por cada jogador e a mensuração das mudanças de direções executadas, podendo também incluir na análise os goleiros de handebol.

\section{CONCLUSÃO}

Concluímos que os principais gestos esportivos realizados pelos jogadores de handebol foram as recepções e os passes. A posição que mais realizou gestos esportivos na equipe de handebol avaliada foi o armador central, seguido do armador esquerdo e direito, e o pivô foi a posição que menos realizou os gestos esportivos avaliados por este estudo. 


\section{Main sporting gestures performed by handball players}

ABSTRACT: This study aimed to quantify the main sporting gestures performed by professional handball players. For the quantitative measurements of the main movements performed by each player, video recordings were made for all games. It was recorded a mean of I.288.0 $(S D=190.7)$ sporting gestures per game. The central ship-owners did a mean of 375.0 $(S D=83.7)$ gestures and the pivot position perform $63.3(S D=21.2)$ gestures per game. The receptions and passes were the main sporting gestures performed by the handball team. The central ship-owner was the position that performed more gestures, followed by the left and right ship-owner. The pivot was the position that performed less sporting gestures by the handball team evaluated.

KEYWORDS: Athletes; athletic performance; motion; video recording.

\section{Principales gestos deportivos realizados por jugadores de balonmano}

RESUMEN: Este estudio tuvo como objetivo cuantificar los principales gestos deportivos realizados por los jugadores de balonmano. Para la cuantificación de los principales movimientos realizados se hizo grabaciones de vídeo y el análisis se realizó para cada jugador. En promedio los jugadores de balonmano realizaron 1.288,0 (DP $=190,7)$ gestos deportivos por juego. Los armadores centrales realizaron promedio de 375,0 (DP = 83,7) y la posición de pivote hizo 63,3 (DP = 21 2) gestos. Las recepciones y los pases fueron los gestos deportivos más ejecutados, e los armadores centrales realizaron más gestos deportivos en el equipo de balonmano, seguido por los armadores izquierdos y derechos. La posición que menos ejecuto gestos deportivos fue lo pivote.

PALABRAS CLAVE: Atletas; rendimiento atlético; movimiento; grabación en video.

\section{REFERÊNCIAS}

ASEMBO, J. M.; WEKESA, M. Injury pattern during team handball competition in east Africa. East African Medical Journal, v. 75, n. 2, p. I13-6, fev. 1998.

FACCA, F. B.; BORSARI, J. R.; NEVES FILHO, F. P. Manual de Educação Física. São Paulo: EPU, 1977.

FERREIRA, FILHO, E.; SOUSA, P. R. C.; GRECO, P. J. Evolução tecnico-tática do handebol ( 1986 a 1995) e suas consequências para o processo de ensino-aprendizagem e treinamento. Revista Mineira de Educação Física, Viçosa, v. 9, n. 2, p. 49-56, out. 2001.

GRECO, P. J. Análise do diagnóstico do nível de rendimento técnico-tático das equipes participantes do Campeonato Sul-Americano de handebol. Kinesis, Santa Maria, v. 6, n. I, p. 43-55, jan./jun. 1990.

HOEBERIGS, J. H.; VAN GALEN, W. C.; PHILIPSEN, H. Pattern of injury in handball and comparison of injured versus noninjured handball players. International Journal of Sports Medicine, Stuttgart, v. 7, n. 6, p. 333-337, dez. 1986. 
JUNGE, A. et al. Sports injuries during the Summer Olympic Games 2008. American Journal of Sports Medicine, Baltimore, v. 37, n. II, p. 2165-72, nov. 2009.

REIS, H. H. B. O ensino do handebol utilizando-se do método parcial. Efdeportes, Buenos Aires, v. 10, n. 2, fev. 2006. Disponível em: < http://www.efdeportes.com/efd93/handebol. htm>. Acesso em: 16 jan. 2012.

SEIL, R. et al. Sports injuries in team handball. A one-year prospective study of sixteen men's senior teams of a superior nonprofessional level. American Journal of Sports Medicine, Baltimore, v. 26, n. 5 , p. $681-7$, set./out. 1998.

TEGNANDER, A. et al. Injuries in Norwegian female elite soccer: a prospective one-season cohort study. Knee Surgery Sports Traumatology Arthroscopy, New York, v. 16, n. 2, p. 194-8, fev. 2008.

TENROLER, C. Handebol: teoria e prática. Rio de Janeiro: Sprint, 2004.

WEDDERKOPP, N. et al. Injuries in young female players in European team handball. Scandinavian Journal of Medicine \& Sciences in Sports, London, v. 7, n. 6, p. 342-7, dez. 1997.

ZAMBERLAN, E. Handebol: escolar e de iniciação. São Paulo: Treinamento Desportivo, 1999.

Recebido: I mar. 20 I I

Aprovado: 13 set. 201 I

Endereço para correspondência:

Luiz Carlos Hespanhol Junior

Rua 24 de Maio, 94

Vila América

Santo André-SP

CEP: 09| | 0- I 50 
ANEXO A

Formulário individual de registro dos gestos esportivos dos jogadores de handebol - Avaliação por Vídeo -

I. Nome e posição:

2. Partida/Jogo:

3. Mensuração do gesto esportivo (faça uma marcação em um quadrado para cada gesto executado, e depois some todas as marcações apresentando o total de gestos):

- Saltos:

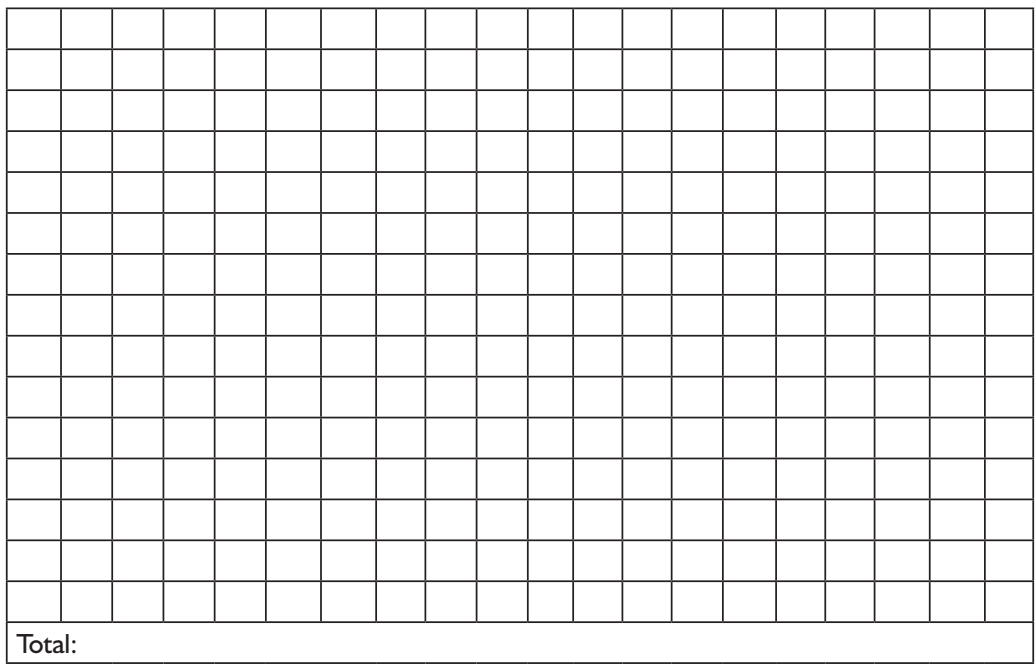

- Arremessos por cima:

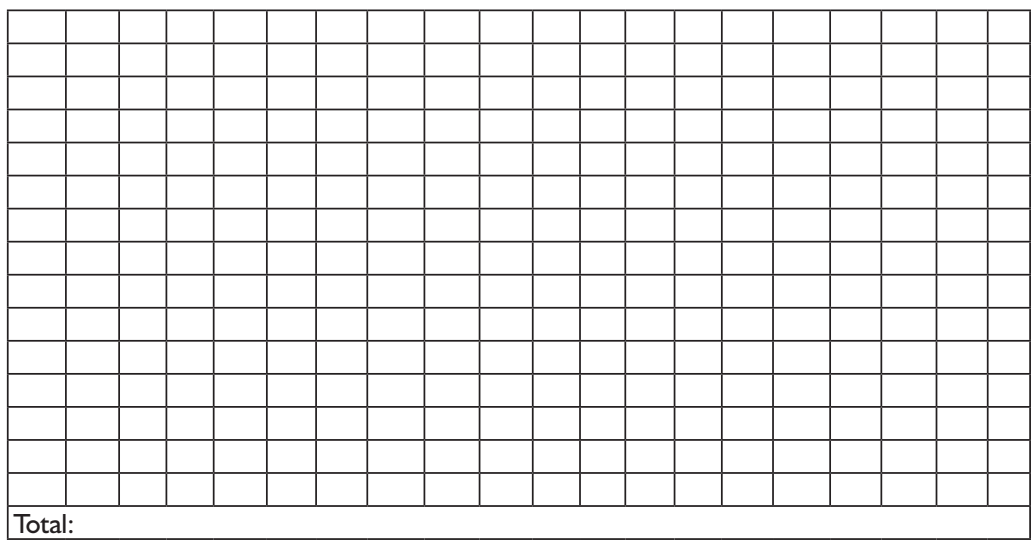


- Arremessos por baixo:

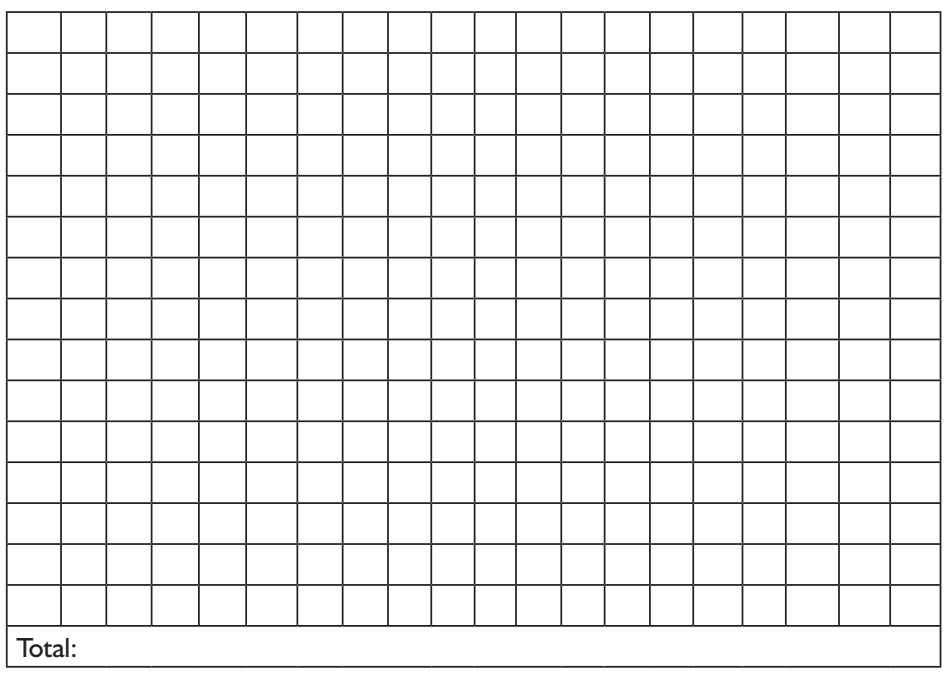

- Passes:

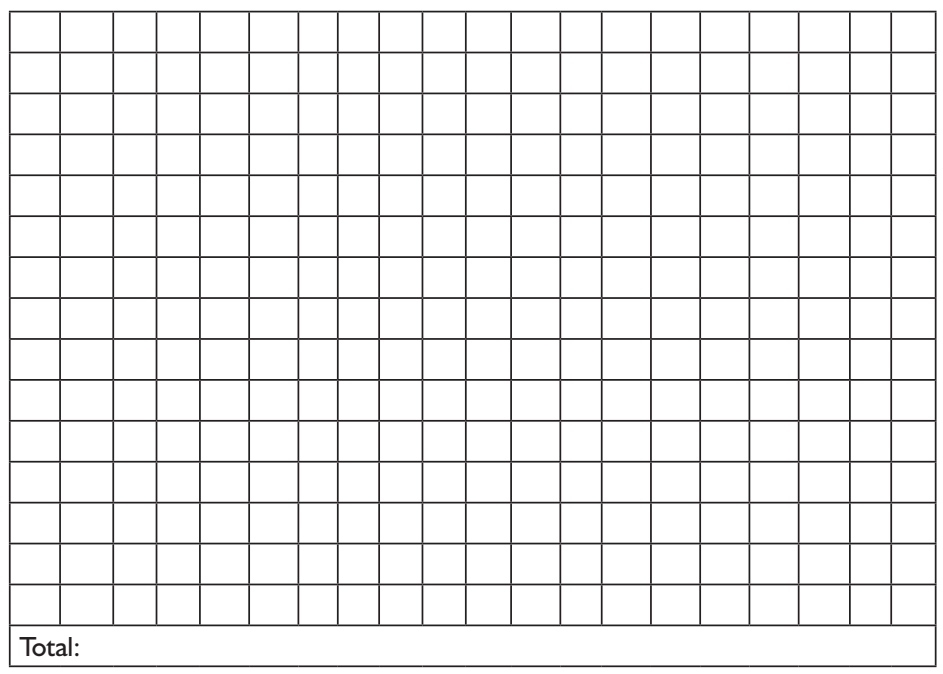


- Recepções:

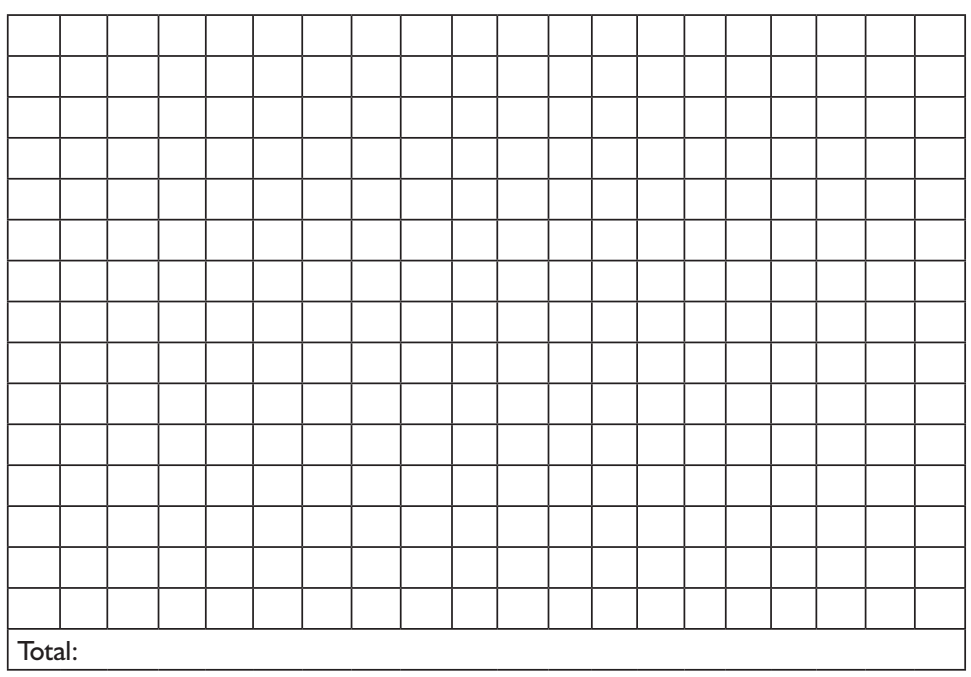

- Fintas com bola:

\begin{tabular}{|l|l|l|l|l|l|l|l|l|l|l|l|l|l|l|l|l|l|l|l|}
\hline & & & & & & & & & & & & & & & & & & & \\
\hline & & & & & & & & & & & & & & & & & & & \\
\hline & & & & & & & & & & & & & & & & & & & \\
\hline & & & & & & & & & & & & & & & & & & & \\
\hline & & & & & & & & & & & & & & & & & & & \\
\hline & & & & & & & & & & & & & & & & & & & \\
\hline & & & & & & & & & & & & & & & & & & & \\
\hline & & & & & & & & & & & & & & & & & & & \\
\hline & & & & & & & & & & & & & & & & & & & \\
\hline & & & & & & & & & & & & & & & & & & & \\
\hline & & & & & & & & & & & & & & & & & & & \\
\hline & & & & & & & & & & & & & & & & & & & \\
\hline & & & & & & & & & & & & & & & & & & & \\
\hline
\end{tabular}

